\title{
Padronização de método de concentração e extração de ácidos nucleicos em amostras de esgoto sanitário: uma ferramenta de baixo custo para ser utilizada na vigilância epidemiológica de SARS-CoV-2
}

\author{
Standardization of the method of concentration and extraction \\ of nucleic acids in wastewater samples: a low-cost tool to be \\ used in epidemiological surveillance of SARS-CoV-2
}

\begin{abstract}
Aline Diniz Cabral ${ }^{\oplus}$, leda Carolina Mantovani Claro ${ }^{1} \odot$, Matheus Ribeiro Augusto ${ }^{1} \odot$, Veronica Nikoluk Friolani' ${ }^{\oplus}$, Cintia de Espindola Bezerra' ${ }^{\oplus}$, Melissa Cristina Pereira Graciosa' ${ }^{\circledR}$,

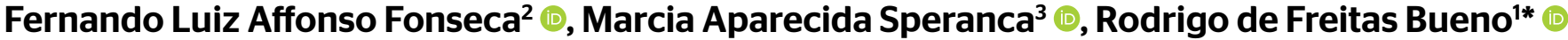

\section{RESUMO}

A vigilância da qualidade dos esgotos sanitários pode representar uma ferramenta complementar para monitoramento de doenças infecciosas e prevenção de surtos epidêmicos, especialmente quando a capacidade para testes clínicos é limitada. Dessa maneira, o presente estudo descreve o detalhamento técnico de um método de baixo custo para a concentração e extração de ácidos nucleicos de amostras de esgoto sanitário como etapa prévia para a detecção de vírus e outros agentes patogênicos. Para validar a metodologia proposta, após as etapas de concentração e extração, analisaram-se a presença do ácido ribonucleico do SARS-CoV-2 (COVID-19) nas amostras, por meio de reação em cadeia da polimerase em tempo real. O ácido ribonucleico do vírus foi detectado em $80 \%$ das amostras de esgoto sanitário analisadas, comprovando o êxito do procedimento metodológico adotado. A detecção precoce de um patógeno associado ao trabalho de equipes multidisciplinares possibilita a prática da vigilância epidemiológica, que auxilia na tomada de decisões na Saúde Única - união indissociável entre a saúde animal, humana e ambiental.

Palavras-chave: saúde única; COVID-19; epidemiologia; esgoto sanitário

\section{ABSTRACT}

Sewage quality surveillance can represent a complementary tool for monitoring infectious diseases and preventing epidemic outbreaks, especially when the capacity for clinical testing is limited. Thus, the present study describes the technical details of a low-cost method for concentrating and extracting nucleic acids from sewage samples, as a preliminary step for the detection of viruses and other pathogens. To validate the proposed methodology, after the concentration and extraction steps, the presence of the SARS coronavirus-2 (COVID-19) in the samples was analyzed using real-time polymerase chain reaction. The virus' ribonucleic acid was detected in $80 \%$ of the sewage samples analyzed, proving the success of the methodological procedure adopted. The early detection of a pathogen associated with the work of multidisciplinary teams allows the practice of epidemiological surveillance, which assists in making decisions about One Health - an inseparable union between animal, human, and environmental health

Keywords: one health; COVID-19; epidemiology; wastewater

Centro de Engenharia, Modelagem e Ciências Sociais Aplicadas, Universidade Federal do ABC - Santo André (SP), Brasil.

²Departamento de Análises Clínicas, Centro Universitário Médico ABC - Santo André (SP), Brasil.

${ }^{3}$ Centro de Ciências Naturais e Humanas, Universidade Federal do ABC Santo André (SP), Brasil.

*Autor correspondente: rodrigo.bueno@ufabc.edu.br

Conflitos de interesse: os autores declaram não haver conflitos de interesse.

Financiamento: Conselho Nacional de Desenvolvimento Científico e Tecnológico (CNPq -Decit/SCTIE no 07/2020 - número do processo: 402432/2O2O-7)

Recebido: 23/10/2O2O - Aceito: 19/11/2O2O - Reg. ABES: 20200370 


\section{INTRODUÇÃO}

A pandemia da COVID-19 tem como agente etiológico o coronavírus SARSCoV-2 de origem zoonótica, que tem alta similaridade genética com espécies de coronavírus de morcegos, de forma similar aos coronavírus causadores da Síndrome Respiratória Aguda do Oriente Médio (MERS) e do SARS-CoV-1. A COVID-19, que já resultou em milhares de óbitos em todo o mundo desde sua identificação na China em dezembro de 2019, constitui-se em um exemplo de emergência de uma zoonose decorrente de ação antrópica, de difícil contenção por sua forma de transmissão (humano a humano por via aérea) e características biológicas. Além da variabilidade nos sintomas, como tosse, febre, dificuldade para respirar, dor de garganta, diarreia e pneumonia, há grande quantidade de indivíduos assintomáticos transmissores do vírus, de modo que a detecção da circulação do vírus e a quarentena são fundamentais para o controle de sua disseminação. A presença de ácidos nucleicos do SARS-CoV-2 foi relatada em fezes e urina de indivíduos infectados e por esse motivo vem sendo avaliada também em esgotos sanitários. No entanto, a via fecal-oral não foi confirmada como rota de transmissão do vírus (CHERNICHARO et al., 2020a; FIOCRUZ, 2020; MEDEMA et al., 2020; NEMUDRY et al., 2020; OPAS, 2020; SUN et al., 2020; WU et al, 2020b; XU et al., 2020; ZHANG et al., 2020).

Nesse contexto, a epidemiologia baseada em águas residuárias (wastewater-based epidemiology - WBE) é uma abordagem inovadora que permite a obtenção de informações sobre a presença de patógenos em grupos populacionais por meio da análise dos dejetos, sendo uma ferramenta proposta em 2001 e aplicada a partir de 2005 de modo a complementar as técnicas existentes para estimar o uso de drogas em uma dada população (KASPRZYK-HORDERN et al., 2014; LU et al., 2020). Atualmente essa ferramenta está sendo utilizada para a vigilância epidemiológica, servindo como um instrumento para planejamento, organização e operacionalização dos serviços de saúde, bem como para a normatização de atividades técnicas relacionadas, o que permite o monitoramento e a avaliação da situação de saúde no território, além de apoiar as decisões da gestão (BRASIL, 2006; BRASIL, 2009; LU et al., 2020).

Geralmente, a etapa limitante nas análises moleculares para a detecção de vírus e outros agentes patogênicos no esgoto sanitário é a de concentração primária. Esgoto sanitário pode ser considerado como aquele que provém principalmente de residências, estabelecimentos comerciais, instituições ou quaisquer edificações que disponham de instalações de banheiros, lavanderias e cozinhas, sejam elas urbanas ou rurais. Compõe-se essencialmente de água de banho, excretas, sabão, detergentes e águas de lavagens. As urinas e fezes, além de outros compostos que podem ocorrer nos esgotos sanitários, constituem $0,1 \%$ das impurezas, sendo o restante $(99,9 \%)$ essencialmente água. O material genético dos vírus e outros microrganismos encontra-se, portanto, muito diluído nessa matriz (TCHOBANOGLOUS et al., 2013).

A efetividade da WBE depende da qualidade dos dados de quantificação dos microrganismos patogênicos, que por sua vez depende da qualidade do produto da concentração primária da amostra (LU et al., 2020). No caso de um vírus com genoma constituído de ácido ribonucleico (RNA), como o SARS-CoV-2, uma nanopartícula de fácil degradação nas condições do esgoto sanitário, a recuperação por concentração torna-se ainda mais difícil. Os principais métodos utilizados para a concentração primária de amostras podem ser divididos em três grandes grupos: adsorção (VIruses ADsorption-ELution - VIRADEL), ultrafiltração e precipitação/separação de fases.
Os métodos de VIRADEL, baseados na filtração em membranas eletrostaticamente carregadas (eletronegativas e eletropositivas), embora sejam muito utilizados para a concentração primária de amostras, têm apresentado algumas desvantagens quando aplicados às amostras de esgoto sanitário. Os compostos orgânicos dissolvidos nas amostras também sofrem adsorção, promovendo a colmatação prematura das membranas e reduzindo a eficiência de recuperação dos vírus (LU et al., 2020). Ahmed et al. (2020) não verificaram a influência negativa da matéria orgânica no pré-tratamento da amostra, mas recomendaram estudos complementares e a adaptação de outros métodos para aumentar a eficiência de recuperação dos vírus.

Os métodos de ultrafiltração já demonstraram adequada eficiência de concentração, especialmente nos equipamentos de fluxo tangencial. No entanto, esses equipamentos são normalmente grandes, imóveis e não se encontram prontamente disponíveis na maioria dos laboratórios de saneamento. Além disso, uma quantidade limitada de estudos demonstrou a aplicabilidade e a viabilidade de tais métodos para a concentração do SARS-CoV-2 (LU et al., 2020).

Os métodos de precipitação, baseados na utilização de polietilenoglicol (PEG), têm demonstrado excelente desempenho na concentração do vírus para amostras de esgoto sanitário, possibilitando excelente recuperação (LU et al., 2020; WU et al., 2020a). Esses métodos ainda oferecem excelente custo-benefício, uma vez que a maioria dos equipamentos e insumos utilizados é normalmente encontrada em laboratórios de saneamento. LU et al. (2020), após analisarem 18 relevantes trabalhos sobre detecção de SARs-CoV-2 no esgoto sanitário, recomendaram o método de precipitação com PEG, especialmente para maiores volumes de amostras e maiores níveis de matéria orgânica e turbidez.

Dessa maneira, o presente manuscrito tem por objetivo compartilhar um método de concentração e extração de ácidos nucleicos para amostras de esgoto sanitário, baseado no método de precipitação com PEG, de baixo custo e que permite a detecção e a quantificação de RNA de SARS-CoV-2 por transcrição reversa seguida de reação em cadeia da polimerase (RT-PCR) em tempo real. O método proposto pode fornecer uma ferramenta complementar à vigilância epidemiológica para o monitoramento de patógenos circulantes e de doenças emergentes/reemergentes.

\section{METODOLOGIA}

\section{Instrumentação e reagentes}

Para a implementação do método de concentração e extração de ácidos nucleicos de amostras de esgoto sanitário, foram necessários equipamentos como cabine de fluxo laminar, centrífuga refrigerada, cabine para RT-PCR, termociclador e equipamento para PCR em tempo real e sistema de eletroforese. Também foram necessários conjuntos de pipetas, ponteiras e reagentes diversos, como agarose, Ácido Etilenodiamino Tetra-Acético (EDTA), PEG8000 e reagentes para biologia molecular, entre eles a polimerase, didesoxirribonucleotídeos (dNTP) e sondas marcadas com fluorocromo.

\section{Amostragem}

As amostras de esgoto sanitário foram coletadas semanalmente, entre os dias 8 de junho de 2020 e 10 de julho de 2020 (cinco semanas consecutivas), na 
estação de tratamento de esgoto do $\mathrm{ABC}$ (ETE ABC), região metropolitana de São Paulo/SP. Foram realizadas amostragens compostas, de 24 horas, por meio de um amostrador automático Hach refrigerado (modelo AWRS AS950), com temperatura de coleta de $4^{\circ} \mathrm{C}$. Ressaltamos aqui que o plano de amostragem é parte fundamental do sucesso da vigilância epidemiológica baseada em águas residuárias. Neste estudo não abordaremos esse aspecto e recomendamos a leitura da Nota Técnica intitulada "Contribuição para elaboração de planos de monitoramento da ocorrência do novo coronavírus no esgoto", publicada recentemente pelo Instituto Nacional de Ciência e Tecnologia - INCT ETEs Sustentáveis (CHERNICHARO et al., 2020b).

\section{Procedimentos metodológicos de concentração e extração}

A concentração de partículas presentes no esgoto sanitário foi realizada por modificação da técnica de concentração com PEG apresentada por Wu et al. (2020a), detalhada a seguir. Uma alíquota de $40 \mathrm{~mL}$ de esgoto bruto homogeneizada foi colocada em um tubo cônico de centrífuga de $50 \mathrm{~mL}$, contendo $4 \mathrm{~g}$ de PEG 8000 ( $8 \%$ w/v, Sigma) e 0,9 g de Cloreto de Sódio (Synth). Como controle de precipitação de ácidos nucleicos, foram acrescentados $2 \mu \mathrm{L}$ de plasmídeo (pET 28a, Novagen). A amostra foi homogeneizada até a completa dissolução dos solutos e então foi submetida a centrifugação por $60 \mathrm{~min}$, a $15.000 \mathrm{~g}$ em temperatura de $4^{\circ} \mathrm{C}$. Após a centrifugação, toda a água foi descartada e o precipitado foi dissolvido em $0,4 \mathrm{~mL}$ de solução tampão salina-fosfato (PBS $0,1 \mathrm{M}, \mathrm{pH} 7,2)$ e transferido para um microtubo de $1,5 \mathrm{~mL}$. Ao precipitado dissolvido em PBS foi acrescentado $1 \mathrm{~mL}$ de fenol ácido (Phoneutria) e, após agitação vigorosa, o composto foi submetido a centrifugação por $10 \mathrm{~min}$ a $12.000 \mathrm{~g} \mathrm{e} 4^{\circ} \mathrm{C}$. Posteriormente, a fase aquosa contendo macromoléculas solúveis foi transferida para um microtubo de $2 \mathrm{~mL}$, ao qual foram acrescentados $1 \mathrm{~mL}$ de trizol homemade (38\% fenol ácido, 0,8 M Isotiocianato de Guanidina, 0,4 M Tiocianato de Amônio, 0,1 M Acetato de Sódio pH 5, 5\% Glicerol) e $200 \mu \mathrm{L}$ de Clorofórmio (Merck). Em sequência, homogeneizou-se vigorosamente e prosseguiu-se com a centrifugação a $4^{\circ} \mathrm{C}$ por 10 min e rotação de $12.000 \mathrm{~g}$. A fase aquosa contendo ácidos nucleicos (DNA e RNA) foi transferida para outro microtubo de $2 \mathrm{~mL}$ contendo $1,5 \mathrm{~mL}$ de etanol absoluto (Merck). O microtubo foi homogeneizado por inversão e submetido à centrifugação refrigerada a $4^{\circ} \mathrm{C}$ por $10 \mathrm{~min}$, a $12.000 \mathrm{~g}$. Descartou-se o sobrenadante e o precipitado foi lavado com $1 \mathrm{~mL}$ de etanol a $70 \%$, homogeneizado por inversão e submetido a centrifugação a $4^{\circ} \mathrm{C}$ por $10 \mathrm{~min}$, a $12.000 \mathrm{~g}$. $\mathrm{O}$ sobrenadante foi descartado e o microtubo foi invertido em papel absorvente, para repousar até a completa secagem por evaporação em temperatura ambiente. Em sequência, foi realizada a dissolução do pellet em $40 \mu \mathrm{L}$ de água ultrapura livre de RNase. O material dissolvido foi armazenado em

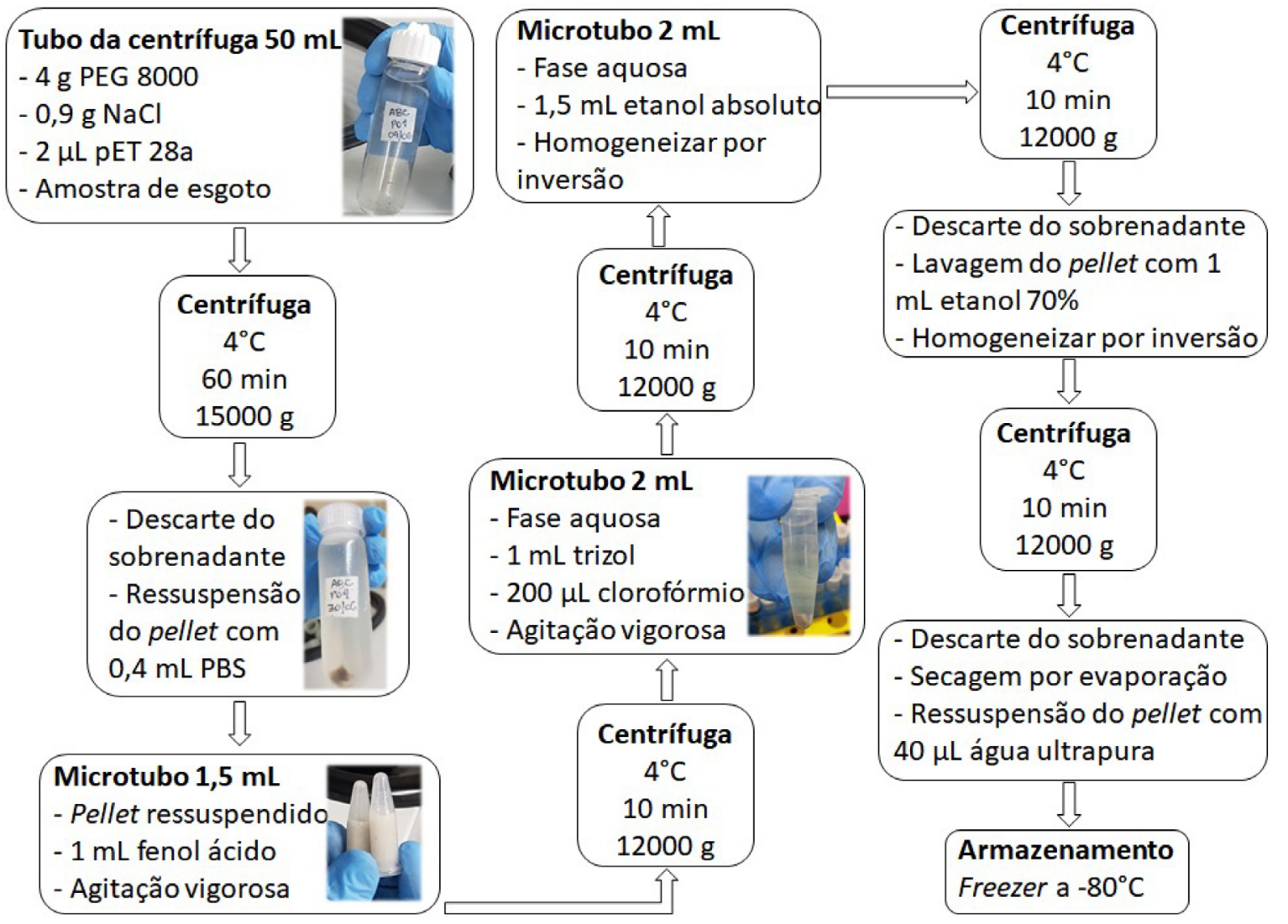

Fonte: elaborada pelos autores.

Figura 1 - Etapas do método de concentração e extração de ácidos nucleicos. 
ultrafreezer a $-80^{\circ} \mathrm{C}$ até o momento do uso. O resumo da metodologia pode ser visualizado na Figura 1.

\section{Detecção do ácido ribonucleico viral e do plasmídeo}

Após as etapas de concentração e purificação de ácidos nucleicos no esgoto sanitário, procedeu-se à etapa de detecção do RNA do SARS-CoV-2 por RT-PCR em tempo real. Para isso, foi utilizado o kit 2019-nCoV TaqMan RT-PCR da Norgen, que detecta o RNA específico para SARS-CoV-2 em uma única etapa de reação, de acordo com as instruções do fabricante. Os alvos de SARS-CoV-2 detectados com o kit da Norgen são os fragmentos denominados N1 e N2, correspondentes ao gene que codifica a proteína do nucleocapsídeo viral, e a RNase $\mathrm{P}$ corresponde ao gene humano utilizado como controle interno.

O protocolo foi descrito pelo Centro de Controle de Doenças dos Estados Unidos da América (CDC). Resumidamente, para cada reação de RT-PCR em tempo real, com cada um dos três alvos, utilizaram-se $10 \mu \mathrm{L}$ de $2 \times$ OneStep RT-PCR Master Mix, 1,5 $\mu \mathrm{L}$ de Primere Probe Mix, 3,5 $\mu \mathrm{L}$ de água livre de nuclease, reagentes contidos no kit e $5 \mu \mathrm{L}$ de amostra de RNA, totalizando o volume final de $20 \mu \mathrm{L}$.

$\mathrm{O}$ kit para reação de RT-PCR em tempo real fornece um controle positivo que contém a sequência dos alvos dos genes que codificam o nucleocapsídeo $\mathrm{nCoV}$ (N1 e N2) e a RNase P humana com o número de cópias conhecido. Para a quantificação das amostras, foram incluídas em cada reação as diluições seriadas dos genes alvo controle utilizando Rotor-Gene Q (Qiagen) e seguindo o programa: ciclo $1-50^{\circ} \mathrm{C}$ por $30 \mathrm{~min}$; ciclo $2-95^{\circ} \mathrm{C}$ por $3 \mathrm{~min}$; ciclo $3-$ $45 \times 95^{\circ} \mathrm{C}$ por $3 \mathrm{~s}$ e $55^{\circ} \mathrm{C}$ por $30 \mathrm{~s}$ (adquirindo a fluorescência no filtro verde, pois as sondas contêm a fluorescência FAM). As amostras são processadas em duplicata, assim como as curvas controle padrão, utilizando-se o equipamento Rotor-Gene Q (Qiagen) para RT-PCR.

Para confirmar a concentração e a extração de ácidos nucleicos, $1 \mu \mathrm{L}$ de plasmídeo (pET 28a) a $100 \mathrm{ng} / \mu \mathrm{L}$ foi adicionado randomicamente em $20 \%$ das amostras antes da centrifugação. A detecção do plasmídeo (pET $28^{\text {a }}$, Novagen) foi realizada por meio da PCR convencional (termociclador Applied Biosystem $\left.\mathrm{s}^{\mathrm{Tw}}\right)$, sendo empregados oligonucleotídeos direcionados à região T7 (Tabela 1).

Para uma reação de $25 \mu \mathrm{L}$ de volume final, foi utilizada a seguinte mistura de reagentes: tampão de reação ( $\mathrm{KCl} 50 \mathrm{mM}$; Tris- $\mathrm{HCl} 10 \mathrm{mM}, \mathrm{pH}$ 9,0), 200 $\mu \mathrm{M}$ de cada nucleotídeo (dATP, dTTP, dCTP, dGTP), 0,10 $\mu \mathrm{M}$ de cada oligonucleotídeo, $2 \mathrm{mM}$ de $\mathrm{MgCl}$, 0,5 unidade de Taq DNA polimerase e $2 \mu \mathrm{L}$ de DNA extraído. Essa mistura foi submetida a uma desnaturação inicial $\left(94^{\circ} \mathrm{C}\right.$ $\left.3^{\prime}\right)$, seguida de 40 ciclos de desnaturação $\left(94^{\circ} \mathrm{C} 30^{\prime \prime}\right)$, hibridização $\left(60^{\circ} \mathrm{C} 30^{\prime \prime}\right)$ e extensão $\left(72^{\circ} \mathrm{C} 45^{\prime \prime}\right)$, finalizando com uma extensão final $\left(72^{\circ} \mathrm{C} 7^{\prime}\right.$ e $\left.4^{\circ} \mathrm{C} \infty\right)$.

A recuperação do plasmídeo foi obtida por meio de eletroforese em gel de agarose $1 \%$, corado com UniSafe Dye ${ }^{\circledast}(20,000$ x Uniscience), sendo as bandas $(\sim 347 \mathrm{pb})$ visualizadas por meio de fotodocumentador UV (L-PIX Loccus).

Tabela 1 - Sequências de oligonucleotídeos.

\begin{tabular}{l|c} 
Oligonucleotideos & Sequência \\
\hline T7_senso & 5' TTAATACGACTCACTATAGGGGAATTG 3' \\
\hline T7_antissenso & 5' GCTAGTTATTGCTCAGCGGTGG 3' \\
\hline
\end{tabular}

Fonte: elaborada pelas autoras.

\section{RESULTADOS E DISCUSSÃO}

\section{Concentração e extração das amostras de esgoto sanitário}

Na Figura 2 está ilustrada a eletroforese em gel de agarose (1\%), demonstrando a recuperação do plasmídeo e validando o método de concentração e extração de ácidos nucleicos de amostras de esgoto sanitário descrito no presente trabalho. Além da precipitação com PEG, existem outros métodos de concentração e extração utilizados por diferentes grupos, entre eles o de adsorção-extração por filtração em membrana eletronegativa ou eletropositiva (LUKASIK et al., 2000; BOSH et al., 2011), ultrafiltração (SOULE et al., 2000; RAJAL et al., 2007; HILL et al., 2007), ultracentrifugação (FORMIGA-CRUZ et al., 2005; HE \& JIANG 2005; ALBINA-GIMENEZ et al., 2006; SILVA et al., 2011) e diversos protocolos para a extração de ácidos nucleicos como sílica, fenol-clorofórmio, além de vários kits comerciais. Assim, o método padronizado, utilizado no presente estudo para a concentração e a extração de ácido nucleico, dispensa o uso de membranas e equipamentos de custo elevado como ultracentrífugas, o que pode ser atrativo para a incorporação em rotinas de laboratório de microbiologia, na detecção de patógenos presentes em amostras de esgoto sanitário.

\section{Detecção do SARS-CoV-2 em amostras de esgoto sanitário}

Os resultados da detecção do SARS-CoV-2 nas amostras do esgoto sanitário afluente à ETE $\mathrm{ABC}$ estão apresentados na Figura 3.

O RNA do SARS-CoV-2 foi detectado em 100\% das amostras das semanas 1, 2, 3 e 5 de monitoramento. Na semana 4, a concentração do material genético do vírus foi abaixo do nível de detecção na amostra de esgoto. Dessa maneira, $80 \%$ das amostras analisadas testaram positivo, comprovando a eficácia do procedimento metodológico proposto para a concentração, extração e detecção do novo coronavírus em amostras de esgoto sanitário.

Na literatura, encontram-se disponíveis diversos artigos baseados na concentração e detecção viral em amostras de esgoto sanitário, e até o momento não há um protocolo único que seja utilizado como padrão para determinar a concentração viral do SARS-CoV-2 em águas (SYMONDS et al., 2014; AHMED et al., 2015, AHMED et al., 2020a,b, KITAJIMA et al., 2020). Os resultados aqui representados são preliminares e ainda serão correlacionados com

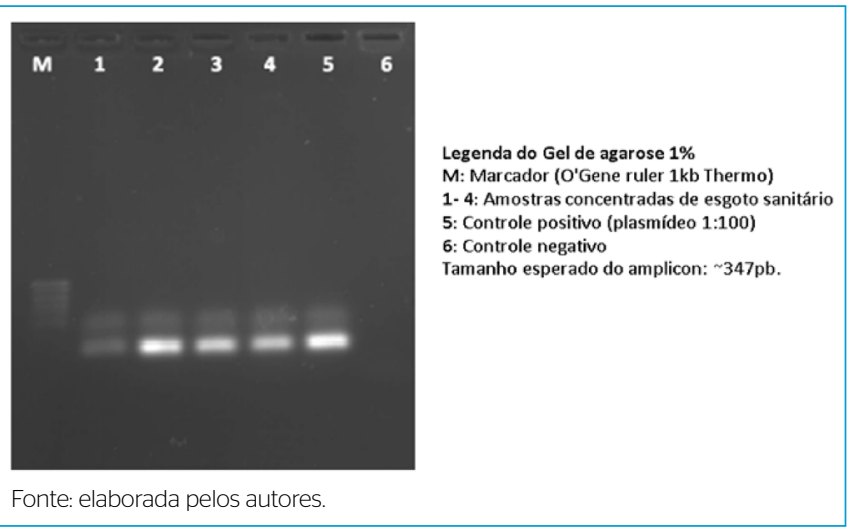

Figura 2 - Amostras de esgoto sanitário concentradas em gel de eletroforese. 


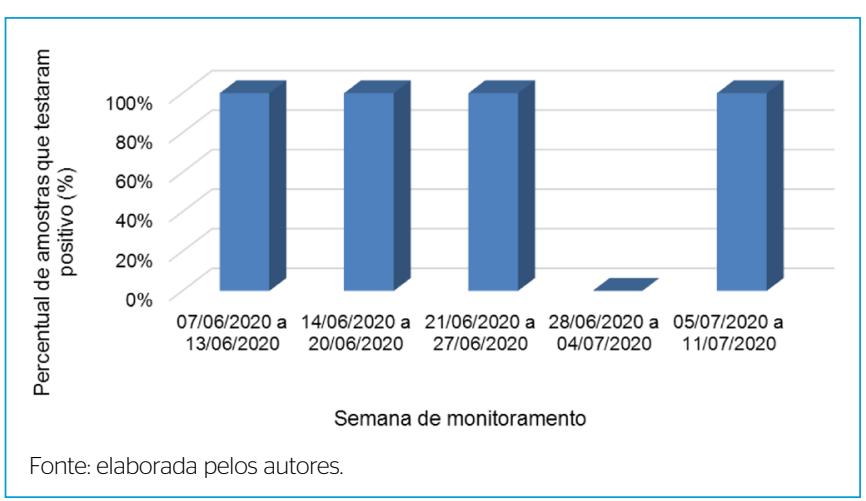

Figura 3 - Percentuais das amostras de esgoto que testaram positivo para a ocorrência do novo coronavírus ao longo de cinco semanas consecutivas de monitoramento.

a concentração viral, bem como com números de infectados em publicações futuras do grupo de pesquisa.

Outros grupos de pesquisa também conseguiram detectar a presença do SARS-CoV-2 em amostras de esgoto sanitário na Holanda (MEDEMA et al., 2020), Espanha (RANDAZZO et al., 2020), Austrália (AHMED et al., 2020), nos Estados Unidos (WU et al., 2020) e até mesmo no Brasil (CHERNICHARO et al., 2020a).

Ahmed et al. (2020), por exemplo, detectaram concentrações do RNA do vírus de 1,9 a 12 cópias/100 mL no esgoto sanitário de Brisbane, Austrália. No entanto, somente $22,2 \%$ das amostras analisadas apresentaram resultados positivos para o SARS-CoV-2. Os autores ainda verificaram inconsistências em alguns resultados quando realizaram comparação entre dois métodos de concentração, filtração em membrana eletronegativa e ultrafiltração.

Randazzo et al. (2020), analisando amostras de esgoto sanitário afluente de ETE instaladas nas principais cidades da região de Murcia, Espanha, detectaram concentrações do RNA do vírus superiores a $10^{4}$ cópias $/ 100 \mathrm{~mL}$. Wu et al. (2020) também detectaram concentrações dessa ordem de magnitude em Massachusetts, Estados Unidos.

No presente estudo, para a ETE ABC foram detectadas concentrações de RNA do vírus na faixa de $8,0 \times 10^{1}$ a 1,3 x $10^{3}$ cópias $/ \mathrm{mL}$, com valores médios de $2,20 \times 10^{2}$. Como ainda não existe uma metodologia padronizada para a concentração e detecção do vírus, verifica-se grande diferença nos resultados de concentração de RNA entre os diferentes trabalhos.

\section{Considerações importantes sobre aplicações da metodologia proposta}

Para a realização de um trabalho epidemiológico, em que se deseje diagnosticar um agente patogênico circulante em esgoto sanitário, é de suma importância estabelecer os pontos de amostragem e qual a população atendida. Após estabelecer a amostragem, é preciso atentar-se ao método de coleta e preservação da amostra até a chegada ao laboratório.

É importante ressaltar que no esgoto sanitário não existe apenas a presença de dejetos humanos, mas também de animais sinantrópicos (roedores, marsupiais, morcegos, pombos e outras aves) e animais de estimação, que podem ser carreados pelas águas pluviais e de lavagem de pisos até os sistemas de esgotamento sanitário.
Na maior parte dos municípios brasileiros, os sistemas de esgotamento sanitário são do tipo separador absoluto (esgoto sanitário e águas pluviais são transportados por diferentes tubulações), porém os agentes patogênicos alcançam as correntes de esgoto sanitário em razão da existência de ligações clandestinas e ocupações irregulares (BERTOLINO et al., 2018).

$\mathrm{O}$ método adotado no laboratório para testar SARS-CoV-2 em esgoto sanitário deve ser simples, acessível e confiável e, tendo em vista a implantação de um programa de vigilância epidemiológico, deve se atentar à capacidade do laboratório e à viabilidade econômica. Em suma, a colaboração entre os grupos de pesquisa neste momento terá um papel importante no desenvolvimento e compartilhamento de protocolos e resultados comparáveis entre regiões geográficas e escalas temporais semelhantes. Uma abordagem multidisciplinar em escala regional é necessária para que resultados oportunos e de alto impacto guiem a comunidade científica e tecnológica e tenham impacto direto na sociedade.

\section{CONCLUSÃO}

Os resultados deste trabalho demonstram que foi possível adaptar e desenvolver um método para a concentração de esgoto sanitário e a recuperação do RNA viral (SARS-CoV-2) de forma eficaz e acessível. Os resultados ainda mostram que foi possível detectar a presença do novo coronavírus em amostras de esgoto na região do $\mathrm{ABC}$ por meio de PCR em tempo real. Essa metodologia pode integrar-se às ferramentas de vigilância epidemiológica de patógenos e pode ser utilizada como uma opção promissora no enfrentamento da COVID-19.

\section{AGRADECIMENTOS}

Os autores agradecem à Universidade Federal do $\mathrm{ABC}$ o apoio à pesquisa (Edital UFABC no 41/2020 - REIT - 11/01). Agradecemos ao INCT ETEs Sustentáveis a parceria em pesquisas em rede. Agradecemos diretamente os recursos financeiros disponibilizados pelo Conselho Nacional de Desenvolvimento Científico e Tecnológico (CNPq), em parceria com o Ministério da Ciência, Tecnologia, Inovações e Comunicações (MCTIC) e o Ministério da Saúde (MS), por meio do Departamento de Ciência e Tecnologia da Secretaria de Ciência, Tecnologia, Inovação e Insumos Estratégicos em Saúde (Decit/SCTIE nº 07/2020 - pesquisas para enfrentamento da COVID-19, suas consequências e outras síndromes respiratórias agudas graves — número do processo: 402432/2020-7).

\section{CONTRIBUIÇÕES DOS AUTORES}

Cabral, A. D.: conceituação, curadoria de dados, análise formal, metodologia, escrita - primeira redação. Claro, I. C. M.: conceituação, curadoria de dados, análise formal, metodologia, escrita - primeira redação. Augusto, M. R.: curadoria de dados, análise formal, escrita - primeira redação. Friolani, V. N.: metodologia, escrita - revisão e edição. Bezerra, C. E.: metodologia, escrita - revisão e edição. Graciosa, M. C. P.: conceituação, metodologia, escrita - revisão e edição. Fonseca, F. L. A.: conceituação, metodologia, supervisão, escrita - revisão e edição. Speranca, M. A.: conceituação, metodologia, supervisão, escrita - revisão e edição. Bueno, R. F.: conceituação, obtenção de financiamento, metodologia, supervisão, escrita - revisão e edição. 


\section{REFERÊNCIAS}

AHMED, W: HARWOOD, V. J.; GYAWALI, P.; SIDHU, J. P.S.; TOZE, S. Comparison of concentration methods for quantitative detection of sewage-associated viral markers in environmental waters. Applied and Environmental Microbiology, v.81, n. 6, p. 2.042-2.049, 2015. https://doi.org/10.1128/AEM.03851-14

AHMED, W.; ANGEL, N.; EDSON, J.; BIBBY, K.; BIVINS, A.; O'BRIEN, J. W.; CHOI, P. M.; KITAJIMA, M.; SIMPSON, S. L.; LI, J.; TSCHARKE, B.; VERHAGEN, R.; SMITH, W. J. M.; ZAUGG, J.; DIERENS, L.; HUGENHOLTZ, P.; THOMAS, K. V.; MUELLER, $J$. F. First confirmed detection of SARS-CoV-2 in untreated wastewater in Australia: a proof of concept for the wastewater surveillance of COVID-19 in the community. Science of the Total Environment, v. 728, 2020a. https://doi. org/10.1016/j.scitotenv.2020.138764

AHMED, W.; BERTSCH, P. M.; BIVINS, A.; BIBBY, K.; FARKAS, K.; GATHERCOLE, A.; HARAMOTO, E.; GYAWALI, P.; KORAJKIC, A.; MCMINN, B. R.; MUELLER, J. F.; SIMPSON, S. L.; SMITH, W. J. M.; SYMONDS, E. M.; THOMAS, K. V.; VERHAGEN, R.; KITAJIMA, M. Comparison of virus concentration methods for the RT-qPCR-based recovery of murine hepatitis virus, a surrogate for SARS-CoV-2 from untreated wastewater. Science of the Total Environment, v. 739, 2020b. https://doi.org/10.1016/j.scitotenv.2020.139960

ALBINANA-GIMENEZ, N.; CLEMENTE-CASARES, P.; BOFILL-MAS, S.; HUNDESA, A.; RIBAS, F.; GIRONES, R. Distribution of human polyomaviruses, adenoviruses, and hepatitis $E$ virus in the environment and in a drinkingwater treatment plant. Environmental Science \& Technology, v. 40, p. 7.4167.422, 2006. https://doi.org/10.1021/es060343i

ARAGÃO, G. C.; OLIVEIRA, D. S.; SANTOS, M. C.; MASCARENHAS, J. P.; OLIVEIRA, C. S.; LINHARES, A. C.; GABBAY, Y. B. Molecular characterization of norovirus, sapovirus and astrovirus in children with acute gastroenteritis from Belém, Pará, Brazil. Rev Pan-Amaz Saúde, v. 1, n. 1, p. 149-158, 2010. http:// doi.org/10.5123/S2176-62232010000100021

BARRELLA, K. M. Pesquisa de virus entéricos humanos em lodos de esgoto originários de duas ETEs do Estado de São Paulo: estabelecimento e avaliação de metodologia para recuperação e detecção viral. São Paulo, SP: USP, 2008. Originalmente apresentada como tese de doutorado, Universidade de São Paulo, 2008.

BERTOLINO, M.; KONDAGESKI, J. H.; WEINSCHUTZ, R. Água de chuva domiciliar no esgoto separador absoluto. Revista DAE, v. 66, n. 213, p. 100108, 2018. https://doi.org/10.4322/dae.2018.035

BOSCH, A., SÁNCHEZ, G.; ABBASZADEGAN, M., CARDUCCI, A., GUIX, S., LE GUYADER, F. S:; NETSHIKWETA, R:; PINTO, R. M:; VAN DER POEL, W. H. M.; RUTJES, S:; SANO, D; TAYLOR, M. B.; VAN ZYL, W. B; RODRIGUEZ-LAZARO, D. KOVAC, K.; SLLEWOOD, J. Analytical methods for virus detection in water and food. Food Anal. Methods, v. 4, p. 4-12, 2011. http://doi.org/10.1007/s12161-010-9161-5

BRASIL. Guia de vigilância epidemiológica. 7a ed. Brasília: Ministério da Saúde, 2009. 816 p.

BRASIL. Guia de vigilância em saúde. 3a ed. Brasília: Ministério da Saúde, 2019. $740 \mathrm{p}$

BRASIL. Vigilância e controle da qualidade da água para consumo humano. 1a ed. Brasília: Ministério da Saúde, 2006. 212 p.

CENTERS FOR DISEASE CONTROL AND PREVENTION (CDC). One Health: history. 2016. Disponível em: https://www.cdc.gov/onehealth/basics/history/ index.html. Acesso em: 30 set. 2021.
CENTERS FOR DISEASE CONTROL AND PREVENTION (CDC). One Health zoonotic diseases. 2017. Disponível em: https://www.cdc.gov/onehealth/ basics/zoonotic-diseases.html. Acesso em: 30 set. 2021.

CHERNICHARO, C. A. L.; ARAÚJO, J. C.:; MOTA FILHO, C. R.: BRESSANI-RIBEIRO, T; CHAMHUM-SILVA, L. A.; LEAL, C. D.; LEROY, D; MACHADO, E.; CORDERO, M. F. E.; AZEVEDO, L. S.; FERNANDES, L.; LEÃO, T.; LAGUARDIA, F.; REIS, M. T. P. MELO, M. C:; AYRIMORAES, S. R. Monitoramento do esgoto como ferramenta de vigilância epidemiológica para controle da COVID-19: estudo de caso na cidade de Belo Horizonte. Engenharia Sanitária e Ambiental, 2020a.

CHERNICHARO, C. A. L.; MOTA FILHO, C. R.; CAVALCANTI, D. L.; ARAÚJO, J. C.; LOBATO, L. C. S.; CHAMHUM-SILVA, L. A.; FUCKNER, M. A.; REIS, M. T. P. AYRIMORAES, S. R.; BRESSANI-RIBEIRO, T. Contribuição para a elaboração de planos de monitoramento da ocorrência do novo coronavírus no esgoto. INCT ETEs Sustentáveis/UFMG; Agência Nacional de Águas; Companhia de Saneamento de Minas Gerais, 202Ob.

FORMIGA-CRUZ, M.; HUNDESA, A.; CLEMENTE-CASARES, P. ALBIÑANAGIMENEZ, N.; ALLARD, A.; GIRONES, R. Nested multiplex PCR assay for detection of human enteric viruses in shellfish and sewage Journal of Virological Methods, v. 125, n. 2, p. 111-118, 2005. https://doi. org/10.1016/j.jviromet.2005.01.009

FUMIAN, T. M.; GUIMARÃES, F. R.; VAZ, B. J. P.; SILVA, M. T. T.; MUYLAERT, F. F BOFILL-MAS, S.; GIRONÉS, R.; LEITE J. P. G.; MIAGOSTOVICH, M. P. Molecular detection, quantification and characterization of human polyomavirus JC from waste water in Rio De Janeiro, Brazil. Journal of Water \& Health, v. 8, n. 3, p. 438-445, 2010. https://doi.org/10.2166/wh.2010.090

FUNDAÇÃO OSWALDO CRUZ (FIOCRUZ). Fiocruz divulga estudo sobre a presença do novo coronavírus em esgotos sanitários. Portal FIOCRUZ, 2020. Disponivel em: http://portal.fiocruz.br/noticia/fiocruz-divulga-estudosobre-presenca-do-novo-coronavirus-em-esgotos-sanitarios. Acesso em 30 set. 2021.

GARRAFA, P. Avaliação da qualidade virológica do efluente doméstico tratado e disponibilizado para reuso na cidade de São Paulo. São Paulo, SP: USP, 2009. Originalmente apresentada como tese de doutorado, Universidade de São Paulo, 2009.

GUIMARÃES, F. R.; FERREIRA, F. F. M.; VIEIRA, C. B. B.; FUMIAN, T. M.; SHUBO, T.; LEITE, J. P. G.; MIAGOSTOVICH, M. P. Molecular detection of human astrovirus in an urban sewage treatment plant in Rio de Janeiro, Brazil. Memórias do Instituto Oswaldo Cruz, v. 103, n. 8, p. 819-823, 2008

HE, J.; JIANG, S. Quantification of Enterococci and Human Adenoviruses in Environmental Samples by Rel-Time PCR. Applied and Environmental Microbiology, v. 71, n. 5, p. 2.250-2.255, 2005. https://doi.org/10.1128\%2FA EM.71.5.2250-2255.2005

HILL, V. R.; KAHLER, A. M.; JOTHIKUMAR, N.; JOHNSON, T. B.; HAHN, D. CROMEANS, T. L. Multistate evaluation of an ultrafiltration-based procedure for simultaneous recovery of enteric microbes in 100-liter tap water samples. Applied and Environmental Microbiology, v. 73, n. 13, p. 4.218-4.225 2007. https://doi.org/10.1128/aem.02713-06

KASPRZYK-HORDERN, B.; BIJLSMA, L.; CASTIGLIONI, S.; COVACI, A.; VOOGT, P.; EMKE, E.; HERNÁNDEZ, F.; ORT, C.; REID, M.; VAN NUJIS, A. L. N.; THOMAS, K. V. Wastewater-based epidemiology for public health monitoring. Water and Sewerage Journal, v. 4, p. 25-26, 2014 
KITAJIMA, M.; AHMED, W.; BIBBY, K.; CARDUCCI, A. L.; GERBA, C. P.; HAMILTON, K. A.; HARAMOTO, E.; ROSE, J. B. SARS-CoV-2 in wastewater: State of the knowledge and research needs. Science of the Total Environment, v. 739, p. 139.076, 2020. https://doi.org/10.1016/j.scitotenv.2020.139076

LU, D.; HUANG, Z.; LUO, J.; ZHANG, X.; SHA, S. Primary concentration - The critical step in implementing the wastewater-based epidemiology for the COVID-19 pandemic: A mini-review. Science of the Total Environment, v. 747, p. 141245, 202O. https://doi.org/10.1016/j.scitotenv.2O20.141245

LUKASIK, L.; SCOTT, T. M.; ANDRYSHAK, D.; FARRAH, S. R. Influence of Salts on Virus Adsorption to Microporous Filters. Applied and Environmental Microbiology, v. 66, n. 7. p. 2.914-2.920, 2000. https://doi.org/10.1128/ AEM.66.7.2914-2920.2000

MEDEMA, G.; HEIJNEN, L.; ELSINGA, G.; ITALIAANDER, R.; BROUWER, A. Presence of SARS-Coronavirus-2 RNA in Sewage and Correlation with Reported COVID-19 Prevalence in the Early Stage of the Epidemic in The Netherlands. Environmental Science \& Technology Letters, v. 7, n. 7. p. 511516, 2020. https://doi.org/10.1021\%2Facs.estlett.Oc00357

MORESCO, V.; DAMAZO, N. A.; BARARDI, C. R. M. Thermal and temporal stability on the enteric viruses infectivity in surface freshwater. Water Supply, v. 16, n. 3, p. 620-627, 2016. https://doi.org/10.2166/ws.2015.171

NEMUDRYI, A.; NEMUDRAIA, A.; WIEGAND, T.; SURYA, K.; BUYUKYORUK, M.; CICHA, C.; VANDERWOOD, K. K.; WILKINSON, R.; WIEDENHEFT, B. Temporal Detection and Phylogenetic Assessment of SARS-CoV-2 in Municipal Wastewater. Cell Reports Medicine, v. 1, n. 6, p. 100.098, 2020. https://doi. org/10.1016/j.xcrm.2020.100098

ORGANIZAÇÃO DAS NAÇÕES UNIDAS (ONU). Agenda 2030. 2017. Disponível em: https://nacoesunidas.org/pos2015/agenda2030/. Acesso em: 30 set. 2021.

ORGANIZACAO MUNDIAL DA SAUDE (OMS). Health Topics: Zoonoses. 2020. Disponível em https://www.who.int/topics/zoonoses/en/. Acesso em: 30 set. 2021.

ORGANIZAÇÃO PAN-AMERICANA DA SAÚDE (OPAS). Folha informativa - COVID-19. Escritório da OPAS e da OMS no Brasil, 2020. Disponível em: http://www.paho.org/bra/index.php?option=com_content\&view=article\&id $=6101$ :covid19\&ltemid=875. Acesso em: 30 set. 2021 .

RAJAL, V. B.; MCSWAIN, B. S.; THOMPSON, D. E.; LEUTENEGGER, C. M.; WUERTZ, S. Molecular quantitative analysis of human viruses in California stormwater. Water Research, v. 41, n. 19, p. 4.287-4.298, 2007. https://doi. org/10.1016/j.watres.2007.06.002

RANDAZZO, W.; TRUCHADO, P.; CUEVAS-FERRANDO, E.; SIMÓN, P.; ALLENDE, A.; SÁNCHEZ, G. SARS-CoV-2 RNA in Wastewater Anticipated COVID-19 Occurrence in a Low Prevalence Area. Water Research, v. 181, p. 115942, 2020. https://doi.org/10.1016\%2Fj.watres.2020.115942

SILVA, H. D.; ANUNCIAÇÃO, C. E.; SANTOS, S. F. O.; GARCIA-ZAPATA, M. T. A. Análise virológica da qualidade da água: uma revisão das metodologias de concentração e detecção viral. Revista Brasileira de Biociências, v. 9, n. 3. p. 405-415, 2011

SOULE, H.; GENOULZ, O.; GRATACAP-CAVALLIER, B.; CHEVALLIER, P.; LIU, J. X. Ultrafiltration and reverse transcription-polymerase chain reaction: an efficient process for poliovirus, rotavirus and hepatitis A virus detection in water. Water Research, v. 34, n. 3, p. 1.063-1.067, 2000. http://doi.org/10.1016/ s0043-1354(99)00197-9

SUN, J.; ZHU, A.; LI, H.; ZHENG, K.; ZHUANG, Z:; CHEN, Z.; SHI, Y.; ZHANG, Z:; CHEN, S.; LIU, X.; DAI, J.; LI, X.; HUANG, S.; HUANG, X.; LUO, L.; WEN, L.; ZHUO, J.; LI, Y.; WANG, Y.; ZHANG, L.; ZHANG, Y.; LI, F.; FENG, L.; CHEN, X.; ZHONG, N.; YANG, Z:; HUANG, J.; ZHAO, J.; LI, Y. Isolation of Infectious SARS-CoV-2 from Urine of a COVID-19 Patient. Emerging Microbes \& Infections, v. 9, n. 1, p. 991-993, 2020. https://doi.org/10.1080/22221751.2020.1760144

SYMONDS, E. M.; VERBYLA, M. E.; LUKASIK, J. O.; KAFLE, R. C.; BREITBART, M.; MIHELCIC, J. R. A case study of enteric virus removal and insights into the associated risk of water reuse for two wastewater treatment pond systems in Bolivia. Water Research, v. 65, p. 257-270, 2014. https://doi. org/10.1016/j.watres.2014.07.032

TCHOBANOGLOUS, G.; STENSEL, H. D.; TSUCHIHASHI, R.; BURTON, F.; ABUORF, M.; BOWDEN, G.; PFRANG, W. Wastewater engineering: treatment and resource recovery. 5a ed. New York: McGraw-Hill, 2013.

UMEDA, L. C. Métodos clássicos e moleculares para avaliação da qualidade virológica de lodo de esgoto e de água de reúso: determinação da eficiência e limites de detecção. São Paulo, SP: USP, 2012. Originalmente apresentada como dissertação de mestrado, Universidade de São Paulo, 2012.

UNITED STATES AGENCY FOR INTERNATIONAL DEVELOPMENT (USAID). USAID launches emerging pandemic threats program. 2009. Disponivel em: https://2012-2017.usaid.gov/news-information/press-releases/usaidlaunches-emerging-pandemic-threats-program. Acesso em: 30 set. 2021.

UNITED STATES ENVIRONMENTAL PROTECTION AGENCY (USEPA). National Primary Drinking Water Regulations. Long Term 2 Enhanced Surface Water Treatment Rule, 40 CFR, parts 9, p. 141-142, 2006.

WORLD HEALTH ORGANIZATION (WHO). Waterborne Zoonoses: Identification, Causes and Control. London: IWA Publishing, 2004.

WU, F.; XIAU, A.; ZHANG, J.; GU, X.; LEE, W. L.; KAUFFMAN, K.; HANAGE, W.; MATUS, M.; GHAELI, N.; ENDO, N.; DUVALLET, C.; MONIZ, K.; ERICKSON, T.; CHAI, P.; THOMPSON, J.; ALM, E. SARSCov-2 titers in wastewater are higher than expected from clinically confirmed cases. MedRxiv, 2020a. https://doi. org/10.1101/2020.04.05.20051540

WU, Y.; GUO, C.; TANG, L.; HONG, Z.; ZHOU, J.; DONG, X.; YIN, H.; XIAO, Q.; TANG, Y.; QU, X.; KUANG, L.; FANG, X:; MISHRA, N.; LU, J.; SHAN, H.; JIANG, G.; HUANG, $X$. Prolonged presence of SARS-CoV-2 viral RNA in faecal samples. The Lancet Gastroenterol Hepatology, v. 5, n. 5, p. 434-435, 2020b. https:// doi.org/10.1016/s2468-1253(20)30083-2

XU, Y.; LI, X.; ZHU, B.; LIANG, H.; FANG, C.; GONG, Y.; GUO, Q.; SUN, X.; ZHAO, D.; SHEN, J.; ZHANG, H.; LIU, H.; XIA, H.; TANG, J.; ZHANG, K.; GONG, S. Characteristics of pediatric SARS-CoV-2 infection and potential evidence for persistent fecal viral shedding. Nature Medicine, v. 26, n. 4, p. 502-505, 2020. https://doi.org/10.1038/s41591-020-0817-4

ZHANG, Y.; CHEN, C.; ZHU, S.; SHU, C.; WANG, D.; SONG, J.; SONG, Y.; ZHEN, W.; FENG, Z.; WU, G.; XU, J.; WENBO, X. Notes from the Field: Isolation of 2019-nCoV from a Stool Specimen of a Laboratory-Confirmed Case of the Coronavirus Disease 2019 (COVID-19). China CDC Weekly, v. 2, n. 8, p.123-124, 2020. https://doi.org/10.46234/ccdcw2020.033 